\title{
Painting plainly
}

Cite as: CMAJ 2018 August 27;190:E1019-20. doi: 10.1503/cmaj.180451

"Every child is an artist. The problem is how to remain an artist once he grows up."- Pablo Picasso

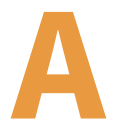

$\mathrm{s}$ I developed my professional identity as a physician, my interest in art lay patiently and unwavering at its foundation. When I was swept up in the storm of medical training, art was my lighthouse shaping my decisions while I navigated a path that incorporated my interests and skills.

Radiology, a visual specialty rooted in anatomy, was a natural choice, although it was difficult initially mainly because of the negative stereotypes that annoyingly cling to it. Although I am outgoing and good with patients, at times during training, I have felt labelled by the radiology stereotype as an uncooperative doctor who prefers to work alone in a dark room. The dissonance this created between

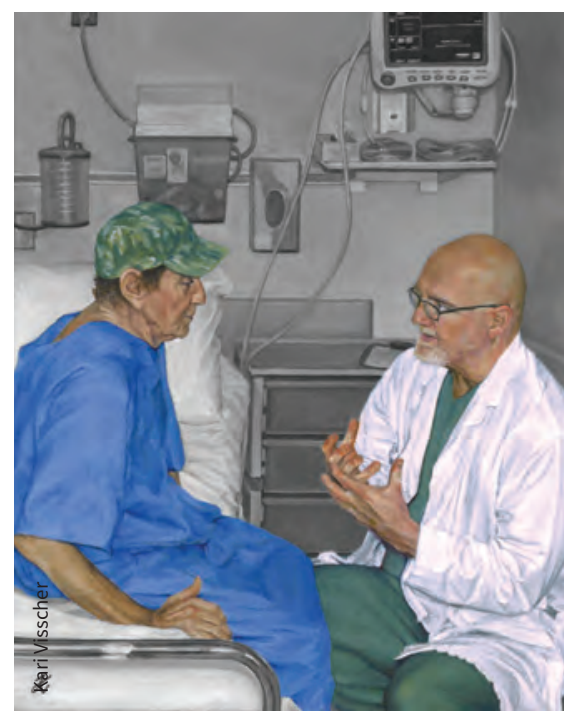

"Consent" (oil on canvas, 9" x 12") depicts an interventional radiologist explaining an important procedure to the patient. The image highlights the importance of taking the time and effort to connect with the patient, answer questions, open lines of communication and validate the patient's health care journey.

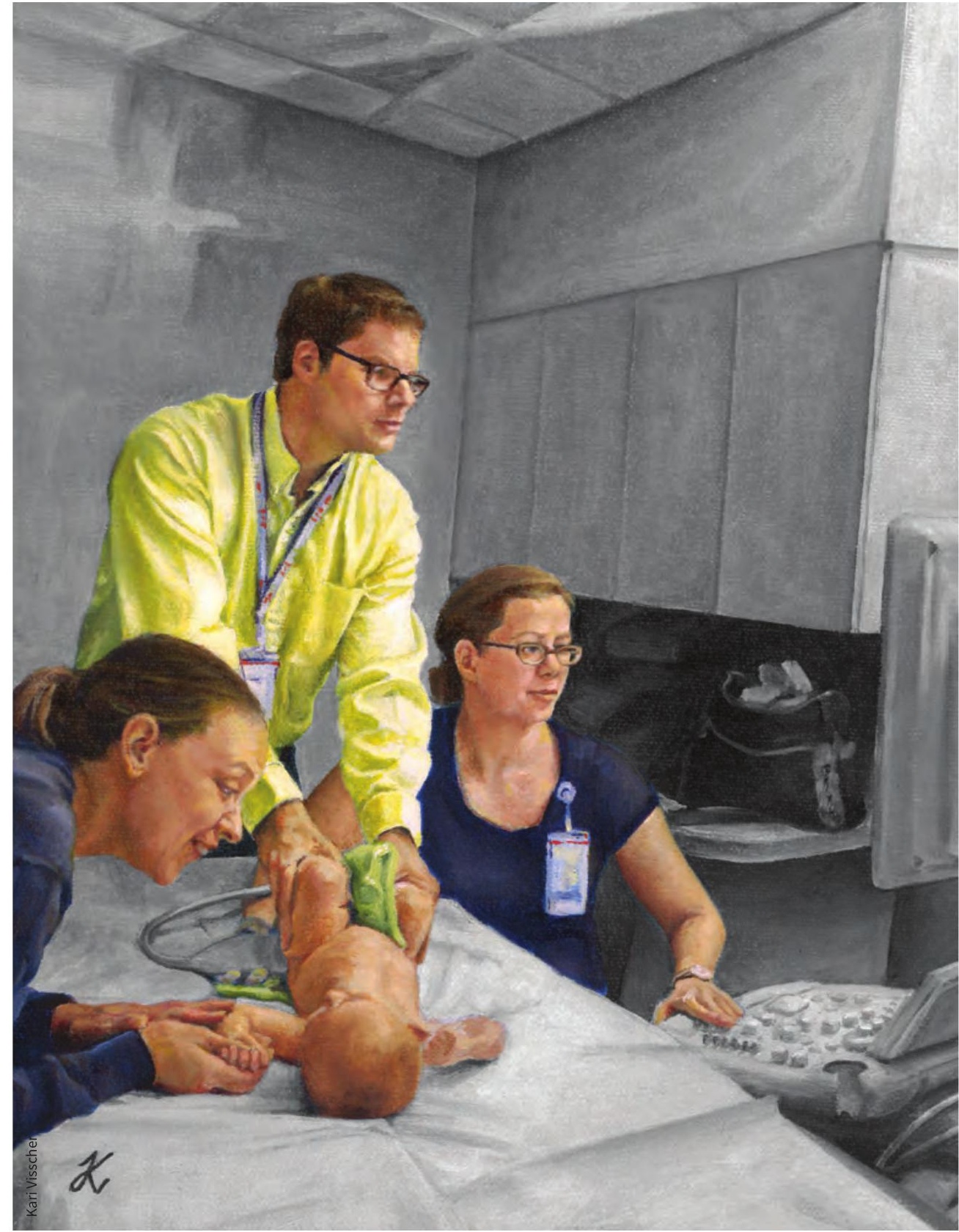

"Hope for Emma" (oil on canvas, 9" x 12") depicts a radiologist (man) doing a dynamic hip manoeuvre on a baby girl who is being treated for hip dysplasia. The ultrasonographer (woman with hand on the machine) is taking the images, and the mother is distracting and soothing her child. In this case, the radiologist was the first to tell the mother that the six-month treatment had worked, and her baby girl could finally be cuddled without a hard, bulky Pavlik harness between them. 

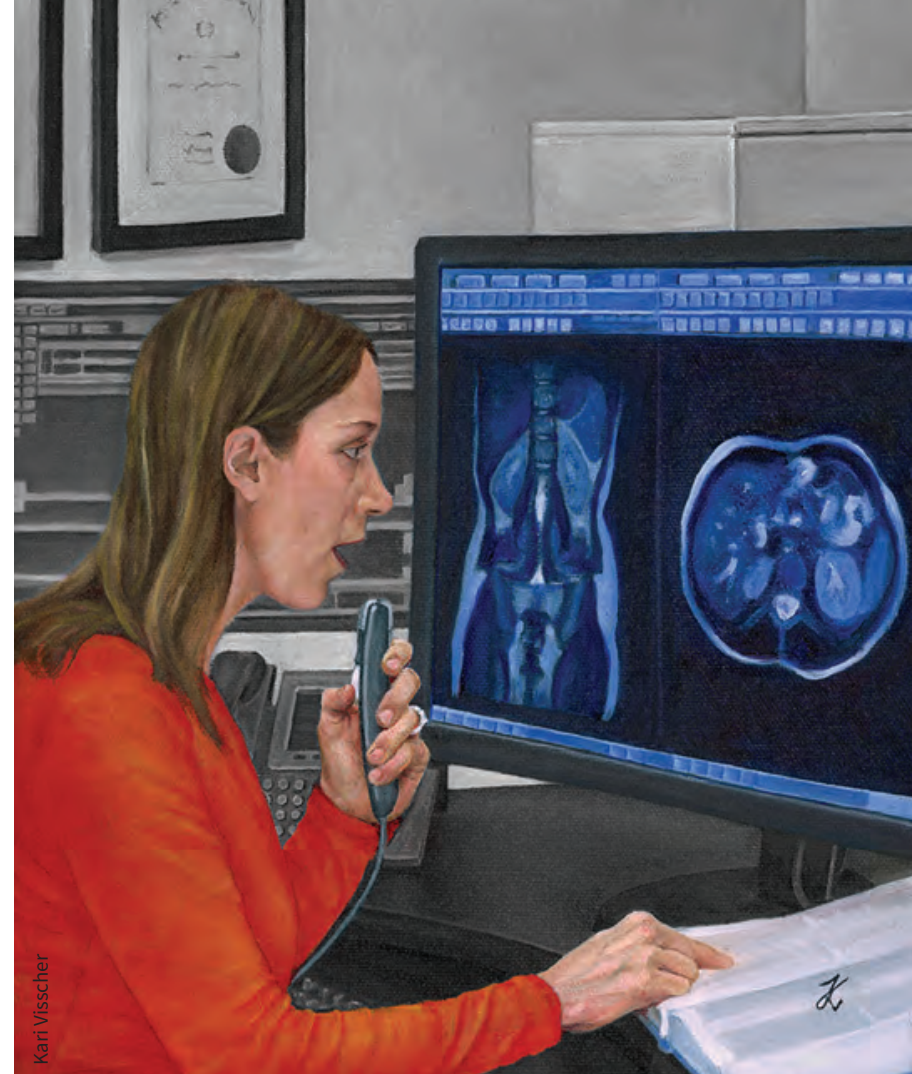

"Diagnosis" (oil on canvas, 9" x 12") depicts a radiologist interpreting an imaging study of a patient, suggesting that some radiologists prefer working in brighter spaces. This piece also demonstrates how we "meet" patients through technology, and care for them by providing the best interpretation and diagnoses possible. what I experienced radiology to be and its stereotypes primed my artistic eye and motivated me to find ways of expressing my day-to-day reality.

This series of oil paintings depict real-life encounters I had during residency, without staging or embellishment. I used grayscale in the background and contrasted it with vibrant colours of the people to emphasize those human interactions that radiologists share with patients, staff and colleagues. The directed gaze of the radiologist to the screen during a procedure serves to accentuate our use of technology to see patients at a level of detail not possible with the unaided human eye. It is through this lens that we can provide a special form of care for our patients. My hope is that through this work, we can open up conversations, challenge stereotypes and broaden our understandings of the role of radiology and radiologists in patient care.

\section{Kari L. Visscher MD MScBMC}

Department of Radiology,

The Ottawa Hospital, Ottawa, Ont.

This article has been peer reviewed.

Every depicted patient and health professional gave their consent for their image to be used.

Competing interests: The author receives payment for sales of prints of the paintings included in this article. 